Fanum

Sociológico
Forum Sociológico

Série II

21 | 2011

Transformação urbana

\title{
Jovens (sub)urbanos: o impacto do hip hop na produção de identidades sociais
}

Leda Barbio

\section{OpenEdition}

1 Journals

Edição electrónica

URL: https://journals.openedition.org/sociologico/450

DOI: 10.4000/sociologico.450

ISSN: 2182-7427

Editora

CICS.NOVA - Centro Interdisciplinar de Ciências Sociais da Universidade Nova de Lisboa

\section{Edição impressa}

Data de publição: 1 dezembro 2011

Paginação: $75-83$

ISSN: 0872-8380

\section{Refêrencia eletrónica}

Leda Barbio, «Jovens (sub)urbanos: o impacto do hip hop na produção de identidades sociais», Forum

Sociológico [Online], 21 | 2011, posto online no dia 05 setembro 2012, consultado o 29 março 2022.

URL: http://journals.openedition.org/sociologico/450 ; DOI: https://doi.org/10.4000/sociologico.450

Este documento foi criado de forma automática no dia 29 março 2022.

(c) CICS.NOVA 


\title{
Jovens (sub)urbanos: o impacto do hip hop na produção de identidades sociais $^{1}$
}

\author{
Leda Barbio
}

\section{Introdução}

1 O estudo em curso pretendia compreender os "subúrbios problemáticos" a partir do estudo de caso de um bairro concreto - o Bairro Amarelo em Almada.

2 Numa primeira fase da investigação pretendia-se perceber de que forma os actores sociais deste espaço concreto construíam os seus modos de vida e as suas identidades. Uma série de diferentes pistas de investigação foram-se revelando pertinentes, numa fase inicial da observação participante. Mediante as entrevistas, conversas informais e observações efectuadas no terreno, e tendo em conta as nossas próprias preferências em termos de métodos e temas de investigação, pareceu-nos pertinente pegar na pista da acção colectiva e da produção das identidades sociais pelos indivíduos.

Assim, por solicitação do terreno fomos dirigindo as leituras para investigações e estudos na área dos Movimentos Sociais e em concreto do movimento hip hop (considerando esta manifestação cultural na sua vertente mais "politizada"). Esta manifestação cultural parece-nos consistir, com efeito, num dos modos possíveis de construção identitária de determinados segmentos de população do espaço urbano concreto que investigamos, ao mesmo tempo que parece, cada vez mais, ganhar contornos de acção colectiva.

4 Assim, redefinindo o nosso objecto de estudo e o objectivo central da pesquisa, poderíamos afirmar que a ideia subjacente e aquela que pretendemos desenvolver neste artigo (embora de forma ainda exploratória nesta fase) é a de:

- Problematizar, em primeiro lugar, a categoria de "jovem" enquanto categoria pertinente, ou não, de análise social²; 
- Analisar as possibilidades no interior de um movimento como o do hip hop no sentido de dinamizar processos de construção identitária junto dos jovens.

\section{Apresentação do Bairro Amarelo (Plano Integrado de Almada)}

O Bairro Amarelo (conhecido por muitos como Pica-Pau Amarelo) foi o primeiro bairro de habitação social construído no concelho de Almada no âmbito do Plano Integrado de Almada, projectado ainda no Estado Novo pelo Fundo de Fomento da Habitação. Apesar de o Plano Integrado de Almada pressupor, como todos os planos integrados na época, uma visão integrada do planeamento urbano (não apenas a construção de habitação, como de infra-estruturas e a criação de condições sociais e ambientais desejáveis a uma "vida digna e plenamente integrada das populações"), com a crise económica de fins dos anos 70 e inícios de 80, acabou por se limitar à construção habitacional (não tendo, sequer, sido construídos todos os fogos inicialmente previstos).

Este bairro foi, assim, construído entre 1975 e 1976 (já em período democrático) e nele foram realojadas as populações migrantes (em grande parte provenientes do Alentejo) que se tinham fixado na zona de Almada nos anos 50/60, em condições de habitação muito precárias, em busca de um lugar numa das indústrias do concelho.

7 Assim, se a população do concelho de Almada está inserida numa das regiões mais desenvolvidas do país e se caracteriza por uma qualidade e nível de vida acima da média nacional, verificamos, contudo, que a população que habita o Bairro Amarelo se encontra longe desta realidade. Este espaço é, de forma semelhante a outras zonas periféricas de Lisboa, um espaço de relegação das camadas mais desfavorecidas da população, tanto das populações rurais que migraram rumo à cidade a partir dos anos 50/60 como, a partir dos anos 70/80, com a vaga de imigrantes dos PALOP e, mais recentemente, do Brasil e dos países do Leste Europeu.

8 A população do Bairro Amarelo é uma população jovem, com baixo nível de escolaridade e taxas preocupantes de mau desempenho e de abandono escolar. Este apresenta-se como um elemento inquietante, já que, havendo poucos jovens a estudar, maior será a probabilidade de a baixa condição social da população do bairro se manter ao longo das gerações. Relativamente aos indicadores de emprego, verificamos, por um lado, elevadas taxas de desemprego no bairro quando comparadas com a média do concelho e do país e, por outro, uma forte prevalência de situações precárias de emprego - trabalhos não declarados e temporários. Mas é sem dúvida pelos grupos de profissão que melhor se pode apreender a baixa condição social objectiva dos habitantes deste bairro, ao apresentar quase $40 \%$ dos trabalhadores inseridos no grupo dos trabalhadores não qualificados e $25 \%$ de operários, artífices e trabalhadores semelhantes, quando os dados do concelho para esses grupos profissionais são, respectivamente, $14 \%$ e $15,4 \%$. Outros factores que importa referir relativamente aos dados apresentados são a maior diversificação étnica que existe na zona do Plano Integrado de Almada, assim como o elevado número de famílias numerosas e a sobreocupação dos alojamentos ${ }^{3}$. 


\section{Juventude(s), Identidade(s) e hip hop}

9 Não podemos pensar este fenómeno do hip hop sem problematizarmos a questão da Juventude, de como tem sido representada ao longo dos tempos pela sociedade adulta, e das teorizações sociológicas que a seu propósito têm sido levadas a cabo.

A Juventude foi muito vista, a nível das Ciências Sociais (Campos, 2010), como um "problema social", relacionada com fenómenos de delinquência, toxicodependência, desemprego, sexualidade, entre outros. Isto é particularmente verdade no que diz respeito aos cientistas da Escola de Chicago e da Sociologia Culturalista que elaboraram, ao longo das décadas de 40 e 50, uma série de estudos que focavam a temática da delinquência juvenil (Shaw e McKay, 1942; Cohen, 1955; entre outros). Escusado será referir que este caucionar científico dos estereótipos já existentes no senso comum vem intensificá-los sobremaneira.

11 Não podemos, contudo, falar em Juventude mas sim em Juventudes. Com efeito, se há um critério etário que aproxima estas pessoas sob a designação de "jovens", existem muitos critérios que os diferenciam (características sociais e económicas, políticas e religiosas, formas de transição para a vida adulta, etc. $)^{4}$.

12 As abordagens culturalistas (que tiveram os seus inícios ainda na década de 20 com a Escola de Chicago, mas que viriam a ter um impulso importante nos anos $70^{5}$, particularmente com a Escola de Birmingham) circulam entre as noções de "cultura juvenil", "subcultura juvenil" e, mais tarde, nos anos 80 e 90, de "tribo urbana". Com particular preponderância surge, sobretudo a partir dos anos 40, o conceito de "subcultura juvenil", que remete para grupos de jovens resistentes. A subcultura seria uma forma de "resistência simbólica" através de um estilo que chocava a sociedade conservadora que desprezava os seus valores e padrões culturais de origem (pobre).

13 Esta abordagem teórica foi muito criticada porque apresentava uma visão de juventude muito baseada na noção de classe social; era uma teoria limitada às "culturas juvenis espectaculares" masculinas e politizadas e as suas análises eram circunscritas a um terreno limitado (Inglaterra), o que a tornou uma análise demasiado parcial (Bennett, 1999; Brown, 2004).

14 Novos conceitos surgiriam ao longo das últimas décadas, tais como o de "estilo de vida" (Pais, 1998), "cena" e "neotribo" (Bennett e Kahn-Harris, 2004). Não sendo este o local para dissecar todos estes conceitos e a maior ou menor pertinência de cada um, interessa-nos resgatar o conceito de "tribos urbanas" e de "identidades dissidentes" pela pertinência de que se revestem para o nosso objecto de estudo particular.

15 Assim, com o conceito de "tribos urbanas" Machado Pais (2004) quer significar: uma "comunhão do sentido de subversão e conversão, com fortes vínculos identitários, a sensação de pertença e inclusão num colectivo de iguais". São pessoas que se sentem diferentes da maioria, distantes dos padrões convencionais e dominantes, o que reforça os laços entre si partilhados. Já o conceito de "identidades dissidentes" remete para grupos nos quais é "como se a identidade reflectisse tensões, contradições e contestações em relação à cultura dominante ou a modos de vida esvaziados de significado" (Pais, 2004: 25).

16 Pensamos que podemos analisar o hip hop de intervenção à luz destas noções de "tribos urbanas" e "identidades dissidentes" se, a par desta "dissidência" lhe juntarmos a noção de "convergência em torno de identidades territoriais, visuais e musicais" (idem). 
17 Por outro lado interessa-nos ainda a definição de "estilo de vida" apresentada por Ricardo Campos:

São empreendimentos pessoais (e, simultaneamente, colectivos) que apelam a uma manipulação de repertórios simbólicos, enriquecidos em permanência pelas indústrias culturais e pelo mercado global, sendo autoconscientemente reflexivos, necessitando de uma constante auto-avaliação e de uma imensa capacidade de improviso. (Campos, 2010: 63)

Com efeito, pudemos verificar que estes jovens se encontram num processo de construção identitária, processo este que se baseia muito não só no que eles pensam acerca deles mesmos, como das representações sociais e expectativas dos "outros significativos". A “identidade é hesitante, mutável, flexível, multissituada e os processos que a constroem são cada vez mais influenciados por múltiplos agentes, canais e meios de comunicação" (Campos, 2010: 64).

Assim sendo, verificamos que podemos classificar o fenómeno do hip hop neste contexto metropolitano tanto como "cultura", como enquanto "subcultura", dependendo da vertente de análise que nos interessar realçar em cada momento. Pode ser considerado cultura porque tem um conjunto de pessoas que partilha uma identidade e sentimento de pertença a um "nós", dispõe de um vocabulário e forma de expressão específicos e dispõe de uma série de regras, valores e condutas que servem para distinguir a comunidade das restantes. Pode ser interpretado também como subcultura, já que se trata de um grupo de pessoas com uma posição subordinada ou mesmo subterrânea num determinado sistema e porque os próprios (hip hoppers) se representam como tal e talvez o mais importante para se denominar algo como subcultura, conforme MacDonald (2001: 152), seja o facto de a própria comunidade se ver e agir como tal, distanciando-se do resto da sociedade.

20 Segundo Ricardo Campos é legítimo, ainda, utilizar tanto o conceito de "subcultura" como o de "tribo", dependendo, mais uma vez, de que aspectos pretendemos acentuar do objecto de estudo. Se verificarmos que o nosso objecto se apresenta como um todo coerente, com uma sustentação ideológica no conflito de classes e a ênfase na questão da "identidade" permanente e estruturada em torno de um conjunto de valores e regras em comum, então neste caso ser-nos-á útil o conceito de "subcultura juvenil". Se, por outro lado, verificarmos que o grupo social que estudamos se apresenta efémero, contraditório, unido pela ligação emocional e aparentemente despolitizado, em constante metamorfose e fusão híbridas, neste caso interessar-nos-á mais falar em "tribos" ou "neotribos" (que direccionam os actores sociais neles envolvidos para "estilos de vida" e consumos relacionados com cada "tribo"). Maffesoli fala mesmo em "comunidade emocional", unida temporariamente de forma afectiva em torno de valores, lugares ou ideais. Aqui fala-se em "lógica de identificação" que põe em cena pessoas de máscaras variáveis em função dos valores e culturas a que se vão associando (e já não numa "identidade", como nos retrata a subcultura juvenil).

21 Várias são as hipóteses teóricas para problematizar este fenómeno, dependendo da forma como este se nos for apresentando ao longo do trabalho de terreno. Será, com efeito, a partir das evidências e dos indícios que o terreno e os protagonistas do fenómeno nos forem dando que poderemos perceber, eventualmente, qual o enquadramento teórico que melhor nos permitirá compreender este fenómeno tão rico e actual da nossa sociedade. 


\section{Movimentos Sociais e o hip hop} se preciosa a contribuição de Melucci (que foi, aliás, discípulo de Touraine). Este autor, pegando na contribuição do seu "mestre", vai desenvolvê-la e afirmar que os novos movimentos sociais não são totalmente singulares e diversos, podendo, de resto, identificar-se uma série de características que lhes são comuns: situam-se fora da esfera do trabalho e da produção; caracterizam-se por uma desconfiança comum em relação ao Estado (partidos e políticos); desenvolvem uma acção crítica e contestatária colocando em questão uma esfera particular da existência social e não a sua totalidade como antes; querem atingir rapidamente essa condição específica pela qual lutam, gerando uma série de práticas alternativas às normativas (exemplo da luta pelo direito ao casamento homossexual); exprimem uma nova cultura política caracterizada por valores de viver melhor, qualidade de vida, direito à diferença; não se articulam entre si, cada luta desenvolvendo-se sozinha; são dominados por particularismos específicos, não se congregando em torno de um objectivo comum de mudança social abrangente.

A ideia de novos movimentos sociais permite, como veremos, que se passe para o centro da investigação e análise as questões identitárias. Estes novos movimentos sociais permitem, segundo Laclau (1986), criar e politizar espaços alternativos de lutas.

Os novos movimentos sociais vão trabalhar questões que antes eram apenas da esfera privada: questões de género e de orientação sexual, questões étnicas e, de uma forma geral, todas as diferenças que querem ser aceites.

É esta importante mudança na abordagem conceptual/teórica dos Movimentos Sociais que permite, pensamos, aplicar esta "arquitectura teórica" ao caso do "hip hop underground". Segundo Melucci, os conflitos sociais actuais já não se localizam na esfera 
económico-industrial, mas sim nas áreas culturais e os novos movimentos sociais "servem" para os actores colectivos revelarem, através da sua acção, os problemas da e para a sociedade. Um dos exemplos que Melucci aponta como emblemáticos desta nova geração de movimentos sociais é o dos movimentos sociais de cunho identitário.

Tendo em conta os testemunhos que fomos ouvindo e as observações que fomos fazendo no bairro em análise e, particularmente, dos actores sociais ligados ao movimento hip hop, o conceito de novos movimentos sociais parece-nos uma ferramenta teórica susceptível de ser aplicada com potencial de compreensão do caso dos subúrbios. Pelo hip hop estes jovens querem mostrar a situação de diferença em que vivem (consideram-se excluídos da sociedade que os oprime e os estigmatiza, situação essa que expõem na sua música e nos seus graffiti $\left.{ }^{6}\right)$, mas também apresentar a sua visão de uma "melhor" sociedade ${ }^{7}$. Através deste movimento almejam, como afirmava Touraine (1990), a possibilidade de uma reconstrução identitária, de serem (re)conhecidos de forma positiva entre pares, ainda que fora dos padrões impostos pela sociedade dominante. Ora este reconhecimento e afirmação identitária fazem-se, neste caso do hip hop, através da afirmação desta "tribo urbana" (Pais, 2004) ${ }^{8}$.

\section{O movimento hip hop}

\section{As raízes do movimento hip hop}

Segundo vários autores, entre os quais Boaventura de Sousa Santos (2001), a década de 70 foi marcada pelo acirrar das condições do capitalismo em diversos países, e com este emergiram novas desigualdades e dificuldades, tanto no campo económico como no social.

Se ao poder económico juntarmos a "dominação simbólica" efectivada pelas classes do poder sobre aqueles que não detêm o poder de se exprimirem de forma "audível", verificamos que muitas camadas da população (especialmente aquelas mais atingidas pelas novas desigualdades sociais) sentem essa falta de controlo sobre a sua existência e o domínio económico/social/cultural que sobre si pesa.

31 Se a maioria dessa população, ainda assim, se mantém "em silêncio", executando pacífica e silenciosamente o seu dia-a-dia, há outras partes dessa população que procuram de alguma forma contrariar, nem que seja de forma simbólica, esse estado de coisas. Dentro desses grupos que se manifestam encontramos o designado "movimento hip hop". Este nasce numa comunidade periférica da cidade de Nova Iorque, no bairro do Bronx, onde os fenómenos da pobreza, desemprego, conflitos étnicos e desigualdade social se faziam sentir de forma premente.

o hip hop surge, assim, como reacção de revolta contra o modelo socioeconómico e cultural hegemónico e contra as condições de vida a que esta comunidade se sentia aprisionada. Estávamos perante uma comunidade que tinha sido realojada e cujas antigas identidades comunitárias tinham sido destruídas. Neste contexto de reestruturação do tecido urbano e de uma nova configuração em termos de comunidades e famílias presentes, vai então emergir, de uma forma alternativa, uma nova identidade colectiva, o movimento hip hop (Bennett, 2000, 2002; Rose, 1994). 


\section{O hip hop hoje}

\section{hop deixou de ser um fenómeno de bairro, especificamente do bairro do Bronx, e passou} a ser um fenómeno mundial. Temos, portanto, a "abertura ao meio exterior" (Simões, 2006) como a primeira grande mudança no fenómeno. minorias étnicas e discriminados socialmente, podemos, por outro lado, observar, entre os rappers, uma elevada prevalência de jovens negros de subúrbio ou de "bairros problemáticos" em geral, com condições socioeconómicas desvantajosas e que sofrem de uma relativamente importante discriminação social e cultural na sociedade dominante ${ }^{11}$.

Assim, neste rap específico observa-se que a "etnicidade" se encontra no próprio código genético do movimento, sendo inclusivamente uma das suas bases de legitimação e de afirmação identitária (tal como acontecia, de resto, com o hip hop "original" que surge no Bronx, EUA, nos anos 70). Para além de esta etnicidade estar patente na mensagem veiculada pelas músicas e na origem dos seus praticantes (maioritariamente oriundos ou descendentes de imigrantes dos PALOP), torna-se evidente pela presença de uma forte influencia, neste rap, da música africana e pelas muitas letras cantadas não em português, mas em crioulo.

"É necessário tugas aprendi ta ama/ Antis di niggas bem aprendi ta odeia." ${ }^{12}$

(excerto de música de um jovem rapper do Bairro Amarelo) 
41 Para além da etnicidade existe ainda uma forte presença das classes mais desfavorecidas e uma forte identidade baseada precisamente no sentimento de pertença a essa condição de classe.

Deste modo, “... o hip hop afigura-se também uma manifestação engajada «politicamente» com assumidas conotações étnicas e classistas" (Simões, 2006: 454). Este "código genético" assumido e glorificado vai fazer com que o discurso do rap de intervenção seja extremamente racializado (claro que variando consoante os rappers) e apresenta como seus principais adversários a sociedade dominante que é, precisamente, a população branca dominante, as classes mais favorecidas, os "capitalistas e racistas" que, no seu entender, reproduzem o estado de coisas da sociedade actual e que promovem a sua exclusão social ${ }^{13}$.

Ka sta fixe por isso en ka sta calado

Se for preciso en ta canta pa choca estado ${ }^{14}$

Polícia tá ataca, tá faze rusga rusga

Tantos bandidos com crime y registos di lei

Justiça usa y abusa ${ }^{15}$

(...)

Niggaz disparam, niggaz disparam

Niggaz não cortam, niggaz não matam

Niggaz não roubam, só se safam

(...)

Fora da lei, dentro da lei

Nigga chora por dentro eu sei

Tenta sair do gueto ok...

(excertos da música "É na street" de jovens rappers do Bairro Amarelo)

Revoltado contra sistema

Revoltado com tendência pró guerra

Pobreza, miséria ta trazê rotina

Rebelde sem juízo, ta sobrevivi na Monte ${ }^{16}$

(excertos da música "Vivência" de jovens rappers do Bairro Amarelo)

Importa ainda referir que estes discursos classistas e etnicizados, de revolta e de crítica social, tendem a ser discursos voltados para o interior, para os seus pares. Estes rappers sentem que o seu dever é despertar aqueles que, estando na mesma situação de exclusão que eles, não estão disso conscientes e precisam de "acordar" e de se revoltar. Daí a sua glorificação do movimento negro dos EUA e de figuras emblemáticas como Martin Luther King, que são muito referidas nas suas letras.

Direcção di mic é para gueto

D.G.B. representa tudo preto

Gueto ou street

Street ou gueto

Gueto ou street revoluçon

Street ou gueto comparaçon

Dedicaçon des son

Pa tudo niggas nhas irmons.

(...)

D.G.B. fala pa gueto cu sentido

Cusa ki sta passa é cusa ki en sata fala

En tem liberdade de espreçon

por isso en ka Sata bem cala. ${ }^{17}$

(excerto de música de um jovem rapper do Bairro Amarelo) 
Cém ressalvar, no entanto, que existem, neste rap de intervenção, excepções à regra $^{18}$ : rappers que têm um discurso transclassista e menos virado para a comunidade negra. Existem mesmo alguns rappers brancos que procuram veicular essa mensagem de revolta sem se conotarem apenas com uma comunidade étnica.

\section{A relação com o espaço}

O hip hop consiste num conjunto de práticas que se encontram, desde as suas origens, intimamente relacionadas com o contexto do bairro, da rua, de espaços que apresentam para os seus praticantes e seguidores um elevado simbolismo e que se constitui como um elemento agregador de identidades e sentimento de pertença.

o bairro constitui, principalmente para os rappers de intervenção, o símbolo da sua exclusão social, da injustiça social e da degradação das condições de vida dos seus pares. Por outro lado, devido a não se sentirem parte da sociedade que os exclui, o bairro, a rua, torna-se então o espaço que eles vão querer transformar no "seu espaço", na sua propriedade, no símbolo da sua união contra a sociedade que os discrimina. $\mathrm{O}$ bairro aparece, então, como o expoente máximo, tal como a sua música, de um mecanismo de "inversão simbólica", isto é, os elementos negativamente conotados pela sociedade e cultura dominante tornam-se os elementos agregadores e construtores de uma identidade positiva destas populações excluídas e que se sentem estigmatizadas.

o espaço do bairro passa, então, para estes jovens e através do hip hop, de "território" unidade territorial definida e delimitada mas vazia de significado social e cultural para "lugar" no sentido antropológico - identitário, relacional e histórico (Augé, 1998). É um "lugar" identitário porque permite configurar as identidades em torno do espaço social e da forma como é apropriado e porque se reveste de significados culturais e de sentimentos de pertença. É relacional porque essa identidade construída na relação com o território faz-se na base das relações sociais estabelecidas e das diversas posições ocupadas pelos actores no campo relacional, nomeadamente as relações de poder e de definição do "nós" e do "outro"19. É histórico, por fim, porque resulta de uma sedimentação de traços culturais e de "estilos de vida" (Pais, 1998) entretanto criados, tal como da configuração de poderes existente e na qual o indivíduo se posiciona (tentando, consoante a sua posição no campo relacional e de poder, manter a estrutura de relações existente ou, pelo contrário, modificá-la).

O espaço tem, então, uma importância muito evidente no hip hop, já que todas as suas práticas são extremamente territorializadas e reflectem (principalmente nas letras da música rap) as vivências dos habitantes do bairro, os problemas sentidos e o dia-a-dia do bairro.

É na street nos vida ta passa

É na street niggaz ta trabalha

É na street qui no ta amanti nos gueto ${ }^{20}$

(excertos da música "É na street" de jovens rappers do Bairro Amarelo)

Os territórios são, inclusive, disputados entre grupos de hip hoppers diferentes, tanto social como simbolicamente (situação esta particularmente relevante no que diz respeito aos graffiti, em que os writers têm espaços "seus", e se alguém "invade" o espaço de outro writer, conflitos podem surgir entre grupos, particularmente entre grupos de bairros diferentes/rivais).

Forum Sociológico, 21 | 2011 
50 Assim, como afirma Simões, “as relações de poder materializam(-se) no espaço tal como a apropriação do espaço se apresenta como critério de afirmação no meio, traduzível em termos do reconhecimento e do estatuto dos protagonistas" (Simões, 2006: 436).

\section{Conclusão}

51 Ao longo deste artigo procurámos, através da problematização acerca da(s) juventude(s) e das várias formas pelas quais esta(s) pode(m) configurar a(s) sua(s) identidade(s), assim como pela identificação das características do movimento hip hop, dos seus actores, dos seus cambiantes ${ }^{21}$ e especificidades locais, direccionar a nossa pesquisa no sentido de perceber se estamos na presença, no nosso terreno de estudo, de alguma forma de construção de uma identidade diversa e espacialmente configurada.

Pensamos que o nosso terreno de estudo, dentro da sua complexidade, compreende mais do que sujeitos passivos e resignados à sua posição de excluídos sociais e populações marginalizadas. Parece-nos que existe entre eles alguma vitalidade, um poder de construção de algo novo, diverso, de uma identidade e de uma estrutura que potencie a sua auto-estima colectiva.

Particularmente entre a população jovem, entre determinados grupos sociais dentro desta população, parece-nos haver, com efeito, um investimento muito grande na construção de uma forma de vida, de um modo de estar e de ver o mundo que os favoreça e os faça sentir parte de uma comunidade.

A questão estará em perceber, adiante neste trabalho de doutoramento, se essa identidade e essa forma de vida, se essa luta se faz tendo por base a condição juvenil, a condição de classe, de etnia, ou alguma forma específica de combinação destes elementos ou de outros que surjam como relevantes.

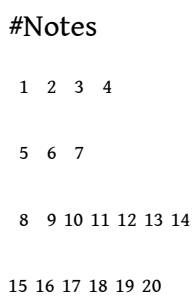

\section{BIBLIOGRAFIA}

AUGÉ, M. (1998), Não lugares - Introdução a uma antropologia da sobremodernidade, Venda Nova, Bertrand Editora.

BENNETT, A. (1999), "Subcultures or Neo-Tribes?: Rethinking the relationship between youth, style and musical taste?", Sociology, 33 (3), pp. 599-617.

BENNETT, A. (2000), Popular Music and Youth Culture: Music, identity and place, Londres, Macmillan. 
BENNETT, A. (2002), “Estilos globais, interpretações locais: reconstruindo o «local» na Sociologia da Cultura Juvenil” in Forum Sociológico, n.ำ 7/8 (II série), pp. 49-67.

BENNETT, A. e K. Kahn-Harris (2004), After subculture: critical studies in contemporary youth culture, Hampshire, Palgrave Macmillan.

BROWN, T. S. (2004), "Subcultures, Pop Music and Politics: Skinheads and «Nazi Rock» in England and Germany", Journal of Social History, 38 (1), pp. 157-178.

CAMPOS, R. (2010), Porque Pintamos a Cidade? Uma Abordagem Etnográfica do Graffiti Urbano, Lisboa, Fim de Século.

COHEN, A. (1955), Delinquent Boys: The Culture of the Gang, Nova Iorque, Free Press.

FRADIQUE, T. (2003), Fixar o Movimento - Representações da música rap em Portugal, Lisboa, Publicações Dom Quixote.

FRADIQUE, T. (2009), “Construir sobre o vazio: a experiência da prática urbana do rap em Portugal" in Actas do VI Colóquio Internacional de Etnocenologia [Em linha]. URL: http:// www.etnocenologia.org/vicoloquio/index.php?

option=com_content\&view=article\&id=123:teresa-fradique-construir-sobre-o-vazio-aexperiencia-da-pratica-urbana-do-rap-em-portugal\&catid=14:paineis-de-pesquisadoresconvidados\&Itemid=186 [cons. a 13 Setembro 2010].

LACLAU, E. (1986), “Os Novos Movimentos Sociais e a pluralidade do social”, Revista Brasileira de Ciências Sociais, 2 (1).

MACDONALD, N. (2001), The Graffiti Subculture. Youth, Masculinity and Identity in London and New York, Hampshire, Palgrave Macmillan.

MAFFESOLI, M. (1987), O Tempo das Tribos - Declínio do Individualismo nas Sociedades de Massa, Rio de Janeiro, Forense Universitária.

MELUCCI, A. (1997). "Juventude, tempo e movimentos sociais”, in Juventude e contemporaneidade. Revista Brasileira de Educação, São Paulo: ANPED, n.os 5 e 6.

PAIS, J. M. (1998), “Gerações e Valores na Sociedade Portuguesa Contemporânea (Introdução)”, in J. M. Pais (ed.), Gerações e Valores na Sociedade Portuguesa Contemporânea, Lisboa, Instituto de Ciências Sociais/Secretaria de Estado da Juventude, pp. 17-58.

PAIS, J. M. e L. M. Blass (coords.) (2004), Tribos Urbanas - Produção Artística e Identidades, Lisboa, Imprensa de Ciências Sociais/ICS-UL.

ROSE, T. (1994), Black noise: Rap Music and Black Culture in Contemporary America, Middletown, Wesleyan University Press.

SANTOS, B. de S. (org.) (2001), Globalização: Fatalidade ou Utopia?, Porto, Afrontamento.

SHAW, C. e H. McKay (1942), Juvenile Delinquency in Urban Areas, Chicago, The University of Chicago Press.

SIMÕES, J. V. (2006), Entre o "real" e o "virtual": representações e práticas culturais juvenis fora e dentro da Internet: o caso do hip-hop português, Dissertação de Doutoramento (Ramo Sociologia da Cultura), Lisboa, FCSH-UNL.

TOURAINE, A. (dir.) (1990), Movimientos Sociales de Hoy - Actores y Analistas, Barcelona, Editorial Hacer.

TOURAINE, A. (2003), Poderemos viver juntos? Iguais e Diferentes, Petrópolis, Vozes. 


\section{NOTAS}

1. O presente artigo foi redigido a partir de uma comunicação apresentada no Encontro Transformação Urbana: Experiências Locais em Novembro de 2010, organizado pelo Grupo de Trabalho Mundos Sociais, Trajectórias e Mobilidades do CesNova. Resulta da pesquisa para a tese de doutoramento que a autora se encontra a realizar, pesquisa essa que se encontra ainda numa fase exploratória, no que diz respeito ao eixo de análise aqui retratado: o hip hop como factor identitário entre certo grupo de jovens do bairro estudado. Assim, o que aqui se exporá será uma análise exploratória aos primeiros materiais recolhidos sobre o tema.

2. Já que é este grupo etário que, no bairro, representa este fenómeno social.

3. Dados recolhidos a partir dos Censos de 2001.

4. Neste artigo daremos conta de uma Juventude relativamente homogeneizada, situação que não reflecte, consideramos, a realidade do bairro em análise, mas que se deve ao estádio inicial da pesquisa sobre estes jovens, que não nos permitiu, ainda, dar conta da heterogeneidade dos mesmos.

5. A nível da teorização sociológica foi a Sociologia dos Estudos Culturais que mais pensou nesta temática da condição juvenil e fê-lo muito em torno da questão das culturas juvenis e das subculturas.

6. De forma bastante significativa, encontramos um graffiti no bairro que diz "A pobreza é muita, mas a fama ainda é mais", referindo-se, por um lado, à situação de pobreza e exclusão da população do bairro face aos padrões de vida dos "outros" (não habitantes do bairro e da zona) e, por outro, à situação de estigmatização de que se sentem alvo pelo "olhar exterior".

7. Como aparece exemplificado no seguinte excerto de entrevista a um jovem do bairro: "Há bué da cenas que têm que mudar. Qual tradição, qual Salazar... isso já passou, já ninguém quer saber disso! o pessoal quer é mudanças, coisas novas. Eh pá, menos esforço e mais qualidade de vida. Isso é que era. Pá, uma qualidade de vida, tás a ver?"

8. Não entraremos, aqui, de novo no debate nem na tentativa de definição do hip hop como "subcultura" ou "tribo" no sentido maffesoliano, já que não nos parece, por um lado, que a fixação da realidade a um conceito ou outro traga maior compreensão sobre o mesmo e porque, por outro, não temos ainda elementos empíricos suficientes que nos permitam fazer tal tipo de escolha conceptual.

9. Referimo-nos, aqui, ao rap produzido de forma independente e que nao é objecto de divulgação no mainstream, mas apenas nos circuitos endógenos (virtual e não virtual) a que só os aficcionados e conhecedores do meio conseguem aceder.

10. É importante desmistificar a ideia de uma oposição essencialista entre hip hop mainstream e hip hop underground. Devemos considerar estes dois "tipos ideais" como pólos definidores de um continuum no qual se localizam os actores sociais, já que estes não apresentam, efectivamente, uma postura irredutível e imune às várias interferências do meio em que estão inseridos. Concretizando, sabemos que certos jovens em alguns momentos, por exemplo, cantam rap em locais "comerciais" para ganhar algum dinheiro e, noutros momentos, investem nas actuações entre os seus pares do underground.

11. Ilustrando isso mesmo, temos a afirmação de um jovem do bairro: "O hip-hop, há bué pessoas que não curtem mesmo, porque nós falamos de coisas que se calhar eles não querem ouvir. Não querem saber que nós tamos a pensar nestas coisas."

12. "É necessário que os Portugueses aprendam a amar/Antes que os pretos aprendam a odiar." 13. Um jovem entrevistado refere, de forma bastante ilustrativa quanto ao que acabámos de afirmar: "As obras deles [referindo-se a quem projecta os bairros sociais] são espectaculares... os gajos fazem com cada obra. Ya. Isto já era problemático, metem-lhe mais zonas problemáticas... é um espectáculo, é bonito... eles querem fazer isto como o Brasil. Que é para terem moral, para chegarem e fazerem o que querem, tás a ver? «Ah isto é muita perigoso, na na na», vais queixar 
aonde? És bandido, és do bairro. Eles são fodidos... enquanto que se não juntassem as coisas mais problemáticas tu conhecias outros mundos, não tavas sempre ali... e depois a comunicação social também joga, a ilusão, tudo isso... engana as pessoas. Também jogam, tem tudo a ver. O que é que esses programas divulgam? Eles nem vêm aqui! Tá tudo a tramar a mesma coisa. Isto tá tudo... tem tudo um único objectivo: o lucro. Querem sempre ter lucro para alguma coisa. Quem tá mal que fique pior e quem não tá mal vai-se safar. É mesmo assim."

14. "Aqui não está fixe por isso é que não estamos calados/ Se for preciso cantamos para chocar o Estado" (tradução livre).

15. "Polícia está a atacar/ tá a fazer rusga, rusga/ Tantos bandidos com crimes e registos na lei/ Justiça usa e abusa" (tradução livre).

16. "Revoltado contra o sistema/ Revoltado com tendência para a guerra/ Pobreza, miséria trazem a rotina/ Rebelde sem juízo sobrevive no Monte [referência ao Monte de Caparica, onde fica o Bairro Amarelo]" (tradução livre).

17. "A direcção do mic [microfone] é para o gueto/ D.G.B. [nome do rapper] representa tudo preto/ Gueto ou street/

/ Street ou gueto/ Gueto ou street revolução/ Gueto ou street comparação/ Dedicações são/ Para todos os negros meus irmãos (...) D.G.B. fala para o gueto com sentido/ as coisas que se estão a passar não se estão a falar/ não há liberdade de expressão/ por isso é que aqui estamos bem calados" (tradução livre).

18. Excepções estas que não foram, todavia, suficientemente numerosas no trabalho de campo entretanto efectuado, pelo que não nos encontramos em condições para, neste momento, conseguir debatê-las em maior profundidade.

19. De forma ilustrativa um jovem entrevistado afirma: "Há hip hop que é tipo códigos, que é tipo de zona para zona. Ya, muito jovem não percebe mas aquilo tamos a dar dicas a um bacano que toda a gente do meio conhece e ninguém apanha, enquanto não souberem a história do bacano..." 20. "É na street que a nossa vida se está a passar/ é na street que os negros estão a trabalhar/ é na street que nós estamos a amar o nosso gueto" (tradução livre).

21. Sendo que não conseguimos ainda, no presente texto, dar conta destes cambiantes, já que a pesquisa de terreno efectuada até ao momento não nos forneceu material empírico suficientemente variado e extenso para que essa análise fosse, aqui, realizada.

\section{RESUMOS}

O presente artigo pretende analisar a relação entre um segmento populacional específico de um bairro de habitação social - os jovens do Bairro Amarelo/Almada - e uma manifestação cultural e/ou política - o hip hop. Num primeiro momento problematiza a noção de juventude e analisa a pertinência dessa categorização para a análise do social e, num segundo momento, introduz o fenómeno do hip hop pensando como este se pode constituir como ferramenta de construção identitária. Alicerçado na observação de terreno de um bairro de habitação social da Área Metropolitana de Lisboa, procurará, então, perceber, no caso concreto, como é que um fenómeno cultural se reveste de cambiantes políticas e de reivindicação identitária no caso de jovens (sub)urbanos.

This paper analyses the relationship between a specific population segment of a social housing district - the youth of Bairro Amarelo/Almada - and a cultural and/or political event - hip hop. 
At first discusses the concept of youth and examines the relevance of this categorization for the social analysis and, second, it introduces the social phenomenon of hip hop wondering how this could constitute a tool for identity construction. Grounded in the field research in a social housing district in the Metropolitan Area of Lisbon, it will search, then, to understand how in this specific case this cultural phenomenon turns political and a symbol of identity demand in the case of young (sub)urban.

\section{ÍNDICE}

Keywords: youth, social housing, hip hop, identity

Palavras-chave: juventude, bairro social, hip hop, identidade

\section{AUTOR}

\section{LEDA BARBIO}

Licenciada em Sociologia pela Faculdade de Ciências Sociais e Humanas da Universidade Nova de Lisboa, doutoranda em Sociologia Urbana, do Território e do Ambiente pela mesma faculdade e bolseira FCT

ledabarbio@fcsh.unl.pt 